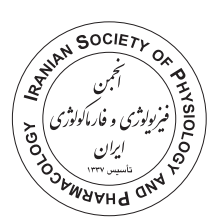

\title{
A study of adverse drug reactions and potential drug-drug interactions in the patients attending the Psychiatric Outpatient Department in a Tertiary Care Teaching Hospital: a cross-sectional study
}

Adit Deshmukh, Sangeeta Dabhade* (iD)

Department of Pharmacology, B. J. Government Medical College and Sassoon General Hospital, Pune, India

\begin{abstract}
Introduction: The objective of this study was to record and analyze the adverse drug reactions (ADRs) due to psychotropic drugs and the potential drug-drug interactions (pDDIs) amongst different psychotropic drugs as well as pDDIs between psychotropic drugs and other co-prescribed drugs by using Medscape software (online).

Methods: A cross sectional study was carried out in patients visiting the Psychiatric Outpatient Department of a Tertiary Care Teaching Hospital. Total 500 prescriptions were analysed for the ADRs and pDDIs.

Results: Total 37 ADRs were observed in 32 (6.4\%) patients. Antipsychotics was the most common group and olanzapine was the most common psychotropic drug suspected of causing ADRs. Tremors was the most common ADR observed. All of the ADRs were nonserious and were in a "Recovering" state when the data was collected. Total $1051 \mathrm{pDDIs}$ were observed in all the 500 prescriptions surveyed, out of which 361 prescriptions were showing at least one pDDI.

Conclusion: The overall incidence of ADRs was not very high (6.4\%), which reiterates the judicious use of the drugs in the study setting. Majority of prescriptions had only 1-2 pDDIs per prescription.
\end{abstract}

\section{Introduction}

Psychiatry is a branch of medicine that deals with mental, emotional or behavioural disorders (Perumal et al., 2018). Psychiatric or mental disorders constitute a significant problem worldwide. Four out of ten health conditions which contribute to the disability adjusted life years, are psychiatric disorders (Grover et al., 2012). Research findings indicate that 30 percent of the global population each year has a mental disorder (Monteiro, 2015). Psychiatric illnesses result in the healthcare services being resorted to at frequent intervals and the costs associated with these services are mostly paid by the patients in developing countries (Grover et al., 2012).

Psychotropic drugs or psychopharmacological agents are those having primary effects on psyche (mental processes) and are used for treatment of psychiatric

\footnotetext{
* Corresponding author: Sangeeta Sanjay Dabhade, sangeetadr99@gmail.com Received 27 September 2020; Revised from 3 January 2021; Accepted 17 January 2021

Citation: Deshmukh A, Dabhade S. A study of adverse drug reactions and potential drug-drug interactions in the patients attending the Psychiatric Outpatient Department in a Tertiary Care Teaching Hospital: a cross-sectional study. Physiology and Pharmacology 2021; 25: 206-213. http://dx.doi.org/10.52547/ppj.25.3.206
} 
disorders (Tripathi, 2013). For the treatment of psychiatric disorders, diverse types of psychotropic drugs are available (Thakkar et al., 2013). In the last 20 years, the development of novel classes of drugs like selective serotonin reuptake inhibitors, atypical anti-psychotics and serotonin-noradrenaline reuptake inhibitors have drastically changed the drug therapy protocols (Perumal et al., 2018).

The literature defines psychotropic polypharmacy as the concurrent prescription of two or more psychiatric drugs to a patient. Psychotropic polypharmacy is a major problem in psychiatric practice, which can lead to development of adverse effects of those drugs in patients (Abebaw et al., 2016).

Psychotropic drugs can cause a number of adverse drug reactions (ADRs) and some of them can be serious or even fatal (Sengupta et al., 2011). Polypharmacy is one of the leading causes of ADRs in patients with psychiatric disorders (Solanke et al., 2013). ADRs associated with psychotropic drugs can lead to lack of compliance, and at times discontinuation of the treatment (Sengupta et al., 2011). Under-reporting is a problem with ADRs due to psychotropic drugs, though their frequency is high. Therefore, pharmacovigilance in psychiatry plays a vital role to ensure therapeutic safety by detecting early alarming signals (Sharma et al., 2014).

A drug-drug interaction (DDI) is an event that occurs when the effects of a drug are modified by another drug that is administered simultaneously (Tesfaye and Nedi, 2017). Patients with psychiatric disorders are at risk for DDIs because most likely they receive chronic treatment with multiple medications (English et al., 2012). Growing evidence attributes DDIs as a major cause of hospital admissions, failure of treatment, avoidable medical complications and associated healthcare costs (Sandson et al., 2005). Keeping all these facts in consideration, the present study was undertaken with the objectives to observe and analyze the ADRs occurring due to psychotropic drugs and to study the potential drug-drug interactions (pDDIs) amongst different psychotropic drugs as well as pDDIs between psychotropic drugs and other co-prescribed drugs by using Medscape software (online) (http://reference.medscape.com/drug-interactionchecker).

\section{Materials and methods}

Study design, study site and period of study
A cross sectional study was carried out in the patients visiting the Psychiatry Out-Patient Department of a Tertiary Care Teaching Hospital, from December 2016 to May 2018.

\section{Ethical considerations}

The Study was initiated after obtaining permission from the Institutional Ethics Committee (BJGMC/IEC/ Pharmac/D-0916122-122). All data collected as a part of this study, was kept strictly confidential and used for the purpose of this study only. As it was a study in psychiatric patients, written informed assent was obtained from the sane guardian/relatives of the patients, instead of patients themselves, before the recruitment of the patients in the study.

\section{Study population}

Total 500 patients were sequentially included in the study as they attended the Psychiatric Outpatient Department. Patients of either sex in the age group of 12 years to 60 years, who were diagnosed to be suffering from any psychiatric illness and prescribed at least one psychotropic drug, and were taking medications since less than or equal to 1 month and those willing to participate in the study were included in the study. whereas the patients having the age less than 12 years and more than 60 years, taking medications for more than 1 month, those with any medical comorbidity, patients having mental and behavioural disorders due to psychoactive substance use, pregnant women and patients/ their relatives not willing to give assent for the study were excluded. A case record form was prepared to collect all the relevant information from the patients.

\section{Detailed research plan}

The collected data was analysed for age wise and gender wise distribution of study population. The patients exhibiting one or more ADRs were classified according to the psychiatric disorders they were suffering from, and the number of patients in each group of psychiatric disorders was calculated. This classification was done according to DSM-5 classification (American Psychiatric Association, 2013). Data of ADRs was recorded on Central Drugs Standard Control Organization suspected adverse drug reaction reporting form (https://cdsco. gov.in/opencms/export/sites/CDSCO_WEB/Pdf documents/Consumer_Section_PDFs/ADRRF_2.pdf). 
The ADRs were collected by the subjective reporting from the patients. Causality assessment was carried out as per Naranjo's algorithm (Naranjo et al., 1981). In Naranjo's algorithm the total score was calculated for every patient and based on that score, the causality of ADR was determined. The interpretation of the total score on Naranjo's algorithm is as follows: Total score 0 (Zero): doubtful; 01 to 04: possible; 05 to 08: probable; $\geq 09$ : definite.

Data of ADRs was analysed as follows: Percentage of ADRs caused by different groups of psychotropic drugs; Most common psychotropic drug causing ADRs; Most common ADR observed due to psychotropic drugs; Causality assessment of all the ADRs due to psychotropic drugs using Naranjo's algorithm; Other parameters for assessment of ADRs including seriousness of ADRs, outcome of ADRs and management of ADRs.

An ADR is called "serious" if it results in any of the following outcomes (Indian Pharmacopoeia Commission, Ghaziabad, 2014): death, life-threatening, hospitalisation/ prolongation of the existing hospital stay, disability, congenital anomaly, required intervention to prevent permanent impairment/damage, or other (when the event does not fit the above conditions, but event may put the patient at risk and may require medical or surgical intervention to prevent one of the above conditions).

Potential drug-drug interactions amongst different psychotropic drugs as well as pDDIs between psycho- tropic drugs and other co-prescribed drugs were studied using Medscape software (online). The pDDIs were then analysed as follows: total number of pDDIs observed in all the 500 prescriptions surveyed; number of prescriptions with no (Zero) pDDIs; number of prescriptions showing at least One pDDI; number of pDDIs observed per patient; range of pDDIs observed per patient.

\section{Results}

\section{Demographic details of study participants}

The age group of 25 to 36 years had maximum number of patients [247 (49.4\%)] out of the total 500 patients enrolled (Fig. 1). The number of male participants [292/500 (58.4\%)] was higher than that of female participants $[208 / 500(41.6 \%)]$.

\section{Pattern of psychiatric disorders}

In this study, total 37 ADRs were observed in 32 patients ( $6.4 \%$ of the total participants). Table 1 demonstrates different psychiatric disorders observed in these 32 patients. Thus, Table 1 shows that the most common group of psychiatric disorders observed in the patients having ADRs was "schizophrenia spectrum and other psychotic disorders".

\section{Adverse drug reactions due to psychotropic drugs}

Figure 2 shows that antipsychotics were the most common drugs causing ADRs ( $70.27 \%$ of all the ADRs), when compared with all other groups. Figure 3 shows

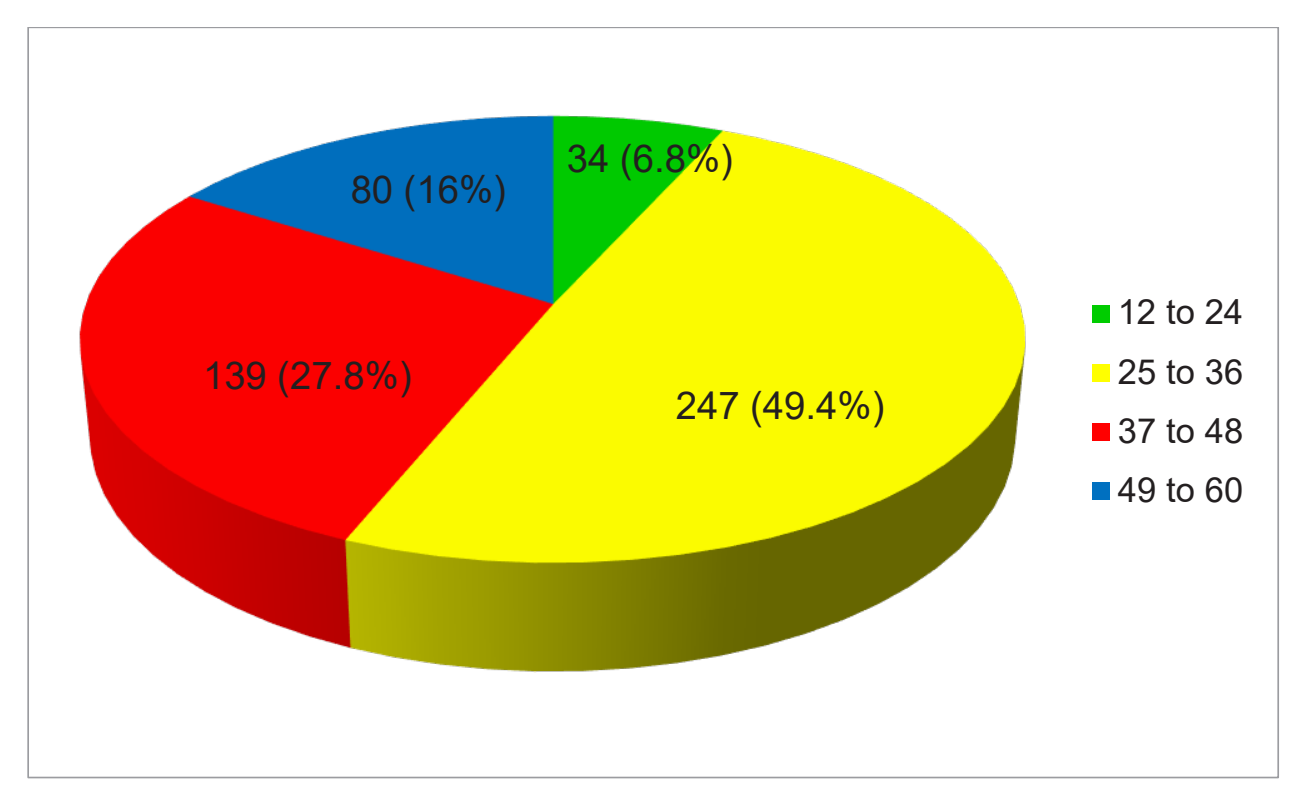

FIGURE 1. Age-wise distribution of study participants. 
TABLE 1: Number of patients suffering from different psychiatric disorders.

\begin{tabular}{lc}
$\begin{array}{l}\text { Psychiatric disorders } \\
\text { as per DSM-5 classification) (American Psychiatric) }\end{array}$ & $\begin{array}{l}\text { Patients- } \\
\text { Number (Percentage) }\end{array}$ \\
$\begin{array}{l}\text { (Association, 2013 } \\
\text { Schizophrenia Spectrum and Other Psychotic } \\
\text { disorders }\end{array}$ & 20 \\
Bipolar and related disorders & 8 \\
\hline Depressive disorders & 1 \\
Other psychiatric disorders & 3 \\
TOTAL & 32 \\
\hline
\end{tabular}

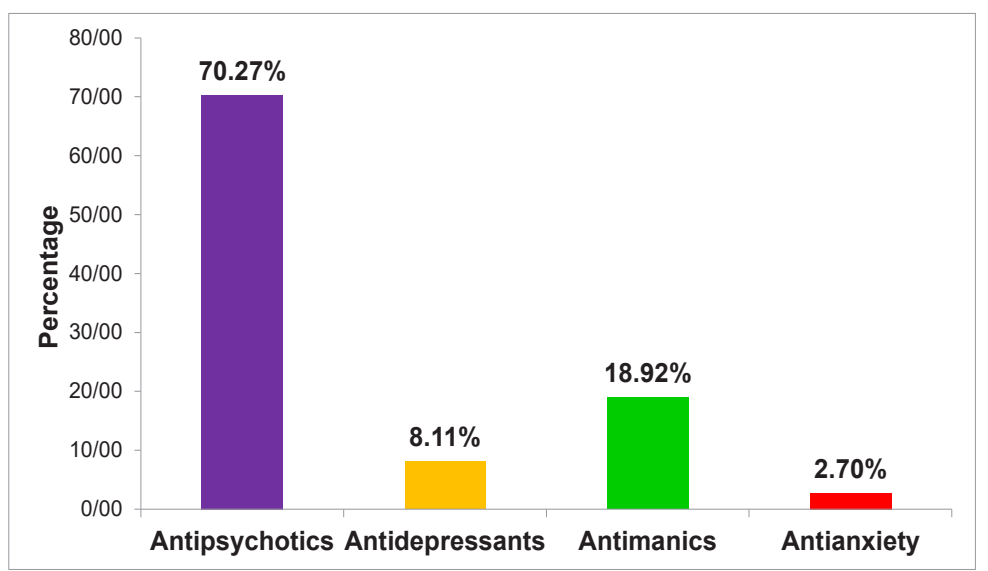

FIGURE 2. Percentage of adverse drug reactions caused by different groups of psychotropic drugs.

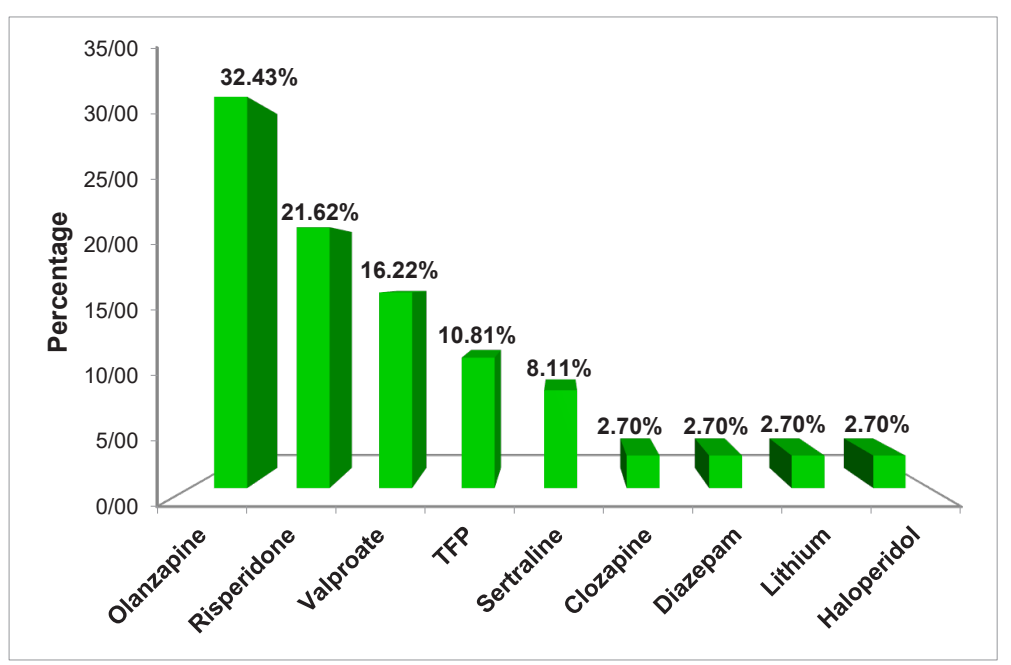

FIGURE 3. Percentage of adverse drug reactions caused by different psychotropic drugs.

that olanzapine (12 ADRs or $32.43 \%$ of total ADRs) was the most common psychotropic drug suspected of causing ADRs. Table 2 shows that "tremors" was the most common ADR observed due to psychotropic drugs.

Causality assessment of all the ADRs due to psychotropic drugs using Naranjo 's algorithm

Out of total 32 cases (patients) of ADR, 29 cases were having causality assessment of ADRs as "possible" and remaining 3 cases had causality as "probable". Among the cases with "possible" causality, risperidone was the most common suspected drug ( 8 cases), whereas among the cases with "probable" causality, olanzapine was the most common suspected drug ( 2 cases). 
TABLE 2: Number and percentage of different adverse drug reactions (ADR) observed due to psychotropic drugs.

\begin{tabular}{|c|c|c|}
\hline ADR & Number & Percentage \\
\hline Tremors (EPS*) & 18 & 48.65 \\
\hline Dry mouth & 5 & 13.51 \\
\hline Constipation & 3 & 8.11 \\
\hline Sedation & 2 & 5.41 \\
\hline Anorexia & 2 & 5.41 \\
\hline Blurred vision & 2 & 5.41 \\
\hline Nausea & 1 & 2.70 \\
\hline Weight gain & 1 & 2.70 \\
\hline Insomnia & 1 & 2.70 \\
\hline Dizziness & 1 & 2.70 \\
\hline Polyuria & 1 & 2.70 \\
\hline TOTAL & 37 & 100 \\
\hline \multicolumn{3}{|c|}{ *EPS: Extrapyramidal symptoms } \\
\hline
\end{tabular}

TABLE 3: Adverse drug reactions in which dose was reduced.

\begin{tabular}{cccc} 
Number & Adverse drug reaction & Suspected drug & Number of patients \\
\hline 1 & Anorexia and Nausea & Sertraline & 1 \\
2 & Dryness of mouth + Blurring of vision & Olanzapine & 1 \\
\hline 3 & Insomnia & Sertraline & 1 \\
4 & Blurring of vision & Olanzapine & 1 \\
\hline
\end{tabular}

TABLE 4: Analysis of potential drug-drug interactions (pDDIs).

\begin{tabular}{|ll|}
\hline Criteria & Result \\
\hline Total number of pDDIs observed in all the 500 prescriptions surveyed & $1051 \mathrm{pDDIs}$ \\
\hline Number of prescriptions with no (Zero) pDDIs & $139(27.8 \%)$ prescriptions \\
\hline Number of prescriptions showing at least One pDDI & $361(72.2 \%)$ prescriptions \\
\hline
\end{tabular}

\section{Other parameters for assessment of ADRs}

Seriousness of ADRs: All of the ADRs reported due to psychotropic drugs were "non-serious". Outcome of ADRs: In all the 32 cases of ADRs, the patients were "recovering" from the ADR when the data was collected. Management of ADRs: The suspected drug was not withdrawn in any of the patients who developed ADRs.

In all the 3 patients who developed constipation as an adverse reaction, suspected drug was olanzapine. All of them were treated for constipation. The dose of the suspected drugs was reduced in following cases as described in Table 3. In remaining 25 cases of ADRs, the dose of the suspected drug was not changed.

\section{Potential drug-drug interactions}

The pDDIs observed using Medscape software were analysed as given in Table 4 and Table 5.

\section{Discussion}

The results obtained from this study demonstrated that the majority of the patients were in their $3^{\text {rd }}$ or $4^{\text {th }}$ decade of life. Some other similar studies done in India also reported the same finding. The overall incidence of ADRs was not very high (6.4\%), which reiterates the 
TABLE 5: Number of potential drug-drug interactions (pDDIs) observed per patient

\begin{tabular}{cc} 
Number of pDDIs per patient & Number of Patients \\
$2-1$ & 220 \\
$5-3$ & 92 \\
$6 \leq$ & 49 \\
TOTAL & 361 \\
\hline
\end{tabular}

judicious use of the drugs in the study setting. Almost $28 \%$ prescriptions were not having any pDDI. Among the remaining prescriptions, majority of the prescriptions had 1 to 2 pDDIs per prescription, which is not a very high number.

In the present study, maximum number of the patients (247 patients or $49.4 \%$ patients) were belonging to the age group of 25 to 36 years. This finding coincides with the study conducted by Thakkar et al. (2013). In the current study, males constituted higher percentage than females. This finding is similar to the study conducted by Mudhaliar et al. (2017). Our study revealed that, among all the psychiatric disorders observed in patients having one or more ADRs, the most common group of psychiatric disorders according to DSM-5 classification was schizophrenia spectrum and other psychotic disorders. The studies conducted by Thakkar et al. (2013) also depicted similar findings.

In this study, out of total 500 patients enrolled, 32 patients $(6.4 \%)$ developed at least one ADR due to psychotropic drugs. This finding is similar to the studies done by Hotha et al. (2016), Solanke et al. (2013) and Prajapati et al. (2013), where the incidence of ADRs due to psychotropic drugs was $4.68 \%, 5.01 \%$ and $8.68 \%$, respectively. Antipsychotics was the commonest group and olanzapine was the most common psychotropic drug suspected of causing ADRs in current study. This finding matched with the study conducted by Gurung et al. (2018). Tremors (extrapyramidal symptoms) was the most common ADR observed due to psychotropic drugs in present study, which is in line with the findings reported by Prajapati et al. (2013) and Gurung et al. (2018). In present study, among the patients who had ADRs due to psychotropic drugs, the number of patients with causality assessment of ADRs as "possible" was more compared to the number of patients who had causality as "probable". Some other studies like Hotha et al. (2016) and Sridhar et al. (2016) also reported similar findings. None of the ADRs reported due to psychotro- pic drugs in our study was fulfilling any of the criteria of "seriousness" (Indian Pharmacopoeia Commission, 2014), that's why all the reported ADRs were "non-serious". In contrast to our findings, the study done by Hotha et al. (2016) reported that $73.26 \%$ ADRs were non-serious, whereas $26.73 \%$ ADRs were considered to be serious. In the present study, for management of ADRs, the suspected drug was not withdrawn in any of the patients who developed ADRs, because the adverse reactions did not significantly disrupt the normal activities of the patients. In contrast to our findings, a study done by Solanke et al. (2013) reported that the suspected drugs had to be withdrawn in cases of some of the ADRs due to psychotropic drugs, while other ADRs subsided on reduction of the dose of the suspected drug.

The literature search did not yield any study regarding pDDIs conducted on OPD basis in psychiatric patients. Therefore, the findings of pDDIs in this study had to be compared with the study done by Ismail et al. (2012) in the indoor psychiatric patients. Total 1051 pDDIs were observed in all the 500 prescriptions surveyed in this study. The study by Ismail et al. (2012) revealed that total 825 pDDIs were identified in 415 patients admitted in the psychiatry ward of a tertiary care hospital. In our study, $72.2 \%$ prescriptions showed at least one pDDI and amongst them majority of the prescriptions had 1 to 2 pDDIs per prescription. Both these findings coincided with those of Ismail et al. (2012). Range of pDDIs observed per patient was 1 to 21 pDDIs per patient. In the study by Ismail et al. (2012) the range was 1 to 10 pDDIs per patient. In patients suffering from psychiatric illnesses, sometimes the principal psychiatric disorder is accompanied by the symptoms of another psychiatric disorder in the same patient. For example, in our study, there were some patients having depressive disorder with anxiety features as the diagnosis. Now such patients have to be treated for depression as well as anxiety, which increases the number of psychotropic drugs prescribed to those patients, which in turn, leads to the 
rise in the number of pDDIs. Same is the case with the patients with some other diagnoses in our study, like mania with psychotic features, paranoid schizophrenia with depressive features, etc. Therefore, the upper limit of the range of pDDIs observed per patient in our study went upto 21 pDDIs per patient.

\section{Limitations}

As this was a cross-sectional study, the follow up of the patients under study was not done. In many patients, depending on their response to the treatment, the medications might be, in future, increased or tapered off. Hence, in later stages, the number of drugs may change, due to which the pattern of ADRs observed and the pDDIs might also change, which was not possible to be documented in this study. This study was conducted in a Tertiary Care Teaching Hospital, due to which the results may differ from the studies conducted in non-teaching and secondary care hospitals as many times they don't have a separate psychiatry OPD. In this study, some of the aspects of pDDIs were not covered, for example, mechanisms of interactions, severity of interactions, etc.

\section{Conclusion}

The ADRs due to psychotropic medications can pose problems to the health of the patients as well as to the compliance of the patients taking those drugs. Psychotropic drugs can interact, either among themselves or with the other co-prescribed medications, which can lead to complications or failure of treatment. Therefore it is essential to identify and analyse the ADRs and pDDIs due to psychotropic drugs.

\section{Acknowledgement}

We sincerely express gratitude towards the Department of Psychiatry (of the institution where the study was carried out) for giving us permission to conduct the study on their patients.

\section{Conflict of interest}

None

\section{References}

Abebaw D, Haile K, Kassaw C, Belete A, Fanta T, Azale T, et al. Pattern of rational use of psychotropic drugs for people with severe mental illness in a mental specialized hospital in Addis Ababa, Ethiopia: a mixed method study. J Fam
Med 2016; 3: 1099.

American Psychiatric Association. Diagnostic and statistical manual of mental disorders. Fifth Edition. Arlington, VA: American Psychiatric Association; 2013. https://doi. org/10.1176/appi.books.9780890425596

English BA, Dortch M, Ereshefsky L, Jhee S. Clinically significant psychotropic drug-drug interactions in the primary care setting. Curr Psychiatry Rep 2012; 14: 376-90. https:// doi.org/10.1007/s11920-012-0284-9

Grover S, Kumar V, Avasthi A, Kulhara P. An audit of first prescription of new patients attending a psychiatry walk-inclinic in north India. Indian J Pharmacol 2012; 44: 319-25. https://doi.org/10.4103/0253-7613.96302

Gurung A, Jaju JB, Pawar GR, Dharmadhikari SC, Solunke RR. Study of drug utilization pattern and adverse drug reactions of psychotropic drugs in psychiatric inpatient department of tertiary care hospital. Int J Basic Clin Pharmacol 2018; 7: 259-65. https://doi.org/10.18203/2319-2003.ijbcp20180095

Hotha PP, Jadav SP, Trivedi HR. Adverse drug reactions: a retrospective review of hospitalized psychiatric patients at tertiary care hospital. Int J Basic Clin Pharmacol 2016; 5:2051-60. https://doi.org/10.18203/2319-2003.ijbcp20163235

Indian Pharmacopoeia Commission, Ghaziabad, 2014. Guidance document for spontaneous adverse drug reaction reporting. Version 1.0 Chapter 3, Reporting of Adverse Drug Reactions; p. 10-18.

Ismail M, Iqbal Z, Khattak MB, Javaid A, Khan MI, Khan $\mathrm{TM}$, et al. Potential drug-drug interactions in psychiatric ward of a tertiary care hospital: prevalence, levels and association with risk factors. Trop J Pharm Res 2012; 11: 28996. https://doi.org/10.4314/tjpr.v11i2.17

Medscape Drug Interaction Checker. Available from: http:// reference.medscape.com/drug-interactionchecker (Cited 6th August 2016).

Monteiro NM. Addressing mental illness in Africa: global health challenges and local opportunities. Comm Psych Glob Persp 2015; 1: 78-95.

Mudhaliar MR, Ghouse IS, Sadubugga P, Narala SR, Chinnakotla V, Yendluri P. Psychotropic drug utilization in psychiatric outpatient department of a tertiary care teaching hospital in India. Int J Res Med Sci 2017; 5: 1612-6. https:// doi.org/10.18203/2320-6012.ijrms20171274

Naranjo CA, Busto U, Sellers EM, Sandor P, Ruiz I, Roberts EA, et al. A method for estimating the probability of Adverse Drug Reactions. Clin Pharmacol Ther 1981; 30: 239-45. 
https://doi.org/10.1038/clpt.1981.154

Perumal VM, Bouddh SK, Nirmal SR, Deshpande A, Singh J, Prabhu N. Drug utilization study and prescribing patterns in psychiatry patients at a tertiary care hospital. Int J Basic Clin Pharmacol. 2018; 7: 774-7. https://doi.org/10.18203/23192003.ijbcp20181185

Prajapati HK, Joshi ND, Trivedi HR, Parmar MC, Jadav SP, Parmar DM, et al. Adverse drug reaction monitoring in psychiatric outpatient department of a tertiary care hospital. Natl J Integr Res Med 2013; 63: 15-48.

Sandson NB, Armstrong SC, Cozza KL. An overview of psychotropic drug-drug interactions. Psychosomatics 2005; 46: 464-94. https://doi.org/10.1176/appi.psy.46.5.464

Sengupta G, Bhowmick S, Hazra A, Datta A, Rahaman M. Adverse drug reaction monitoring in psychiatry out-patient department of an Indian teaching hospital. Indian J Pharmacol 2011; 43: 36-9. https://doi.org/10.4103/02537613.75664

Sharma T, Vishwakarma K, Dhasmana DC, Gupta R, Kalra J, Sharma U. Adverse drug reaction monitoring in psychiatry outpatient department of a tertiary care teaching hospital. JK Science 2014; 16: 156-60.

Solanke B, Mahatme MS, Dakhale G, Hiware S, Shrivastava M, Waradkar P. Adverse drug reaction profile at psychiatry out-patient department of a tertiary referral centre in Central
India. Int J Basic Clin Pharmacol 2013; 2: 341-3. https:// doi.org/10.5455/2319-2003.ijbcp20130623

Sridhar SB, Al-Thamer SS, Jabbar R. Monitoring of adverse drug reactions in psychiatry outpatient department of a Secondary Care Hospital of Ras $\mathrm{Al}$ Khaimah, UAE. J Basic Clin Pharma 2016; 7: 80-86. https://doi.org/10.4103/0976-0105.183263

Suspected Adverse Drug Reaction Reporting Form. Available from: https://cdsco.gov.in/opencms/export/sites/CDSCO_WEB/Pdf documents/Consumer_Section_PDFs/ ADRRF_2.pdf

Tesfaye ZT, Nedi T. Potential drug-drug interactions in inpatients treated at the Internal medicine ward of Tikur Anbessa Specialized Hospital. Drug Healthc Patient Saf 2017; 9: 71-6. https://doi.org/10.2147/DHPS.S126336

Thakkar KB, Jain MM, Billa G, Joshi A, Khobragade AA. A Drug utilization study of psychotropic drugs prescribed in the psychiatry outpatient department of a tertiary care hospital. J Clin Diagn Res 2013; 7: 2759-64. https://doi. org/10.7860/JCDR/2013/6760.3885

Tripathi KD. Essentials of Medical Pharmacology. 8th Edition. New Delhi: Jaypee Brothers; 2013. Chapter 32, Drugs Used in Mental Illness: Antipsychotic and Antimanic Drugs; p.462-80. https://doi.org/10.5005/jp/books/12021_34 